\title{
Vulnerabilidade externa e composição da posição internacional de investimentos: Brasil 2001-2010
}

\section{PAULO VAN NOIJE*}

External vulnerability and composition of the Brazilian International Investment Position: 2001-2010. The aim of this paper is to indicate that there was a significant change in the composition of the Brazilian International Investment Position in the period 2001-2010: international reserves became higher than the external debt and decreased the share of foreign liabilities denominated in foreign currency, getting smaller that the participation of the external liabilities denominated in domestic currency. These tend to suffer a double devaluation (prices and exchange rates) in times of crisis, thus characterizing the reduction of the external vulnerability in the financial sphere as evidenced in the global crisis hatched in 2008.

Keywords: International Investment Position; external vulnerability; 2008 global crisis; Brazilian economy; international reserves.

JEL Classification: E00; F21; F34; H12.

\section{INTRODUÇÃO}

A vulnerabilidade externa ${ }^{1}$ é um dos assuntos mais tratados na área econômica e existem diversas esferas em que se manifesta: comercial, produtivo-tecnológica e monetário-financeira. Contudo, geralmente as análises sobre o tema são focadas na questão do comércio exterior e acabam desconsiderando a questão patrimonial (Gonçalves, 2005). Portanto, partindo da análise da esfera financeira, pretende-se

\footnotetext{
* Doutorando em Teoria Econômica pela Unicamp e Professor da Facamp. E-mail: paulovannoije@ yahoo.com.br. Submetido: 19/novembro/2012; Aprovado: 16/setembro/2013. O autor agradece os comentários e sugestões dos membros dos grupos de pesquisa que participa: Centro de Estudos de Conjuntura e Política Econômica-CECON-Unicamp; Desenvolvimento Econômico e Política EconomicaDEPE (PUC-SP); Moeda, Finanças e Desenvolvimento Econômico-MFDE (PUC-SP). Os erros e omissões porventura remanescentes são de responsabilidade exclusiva do autor.

1 "Vulnerabilidade externa é a probabilidade de resistência a pressões, fatores desestabilizadores e choques externos” (Gonçalves, 1999, p. 59).
} 
inferir de que forma a composição e a magnitude dos estoques externos influenciam a vulnerabilidade externa.

No Brasil, em termos históricos, pode-se observar que a economia é dependente dos financiamentos estrangeiros para fechar suas contas externas, se constituindo essa condição, portanto, em uma das causas da vulnerabilidade externa brasileira, sobretudo em momentos de reversão do contexto internacional em que uma situação de abundância de liquidez se modifica para uma de escassez, fazendo com que a ameaça de saída de capitais estrangeiros - quando os investidores externos decidem repatriar os recursos que constituem o passivo externo doméstico - potencialize e acabe manifestando a vulnerabilidade externa brasileira.

Pode se considerar que a acumulação de um passivo externo líquido elevado significa o aumento da vulnerabilidade externa, levando à diminuição do poder efetivo e uma perda de autonomia na política econômica. Porém, além dessa análise quantitativa, também é necessário uma análise qualitativa dos estoques externos, através da apreciação de sua composição.

Sobretudo diante do fato de que a dinâmica de evolução dos estoques externos passa a depender cada vez mais das mudanças de valor dos mesmos, no sentido de que esta variação adquire certa autonomia em relação aos saldos das transações correntes. Tal processo é gerado por dois fatores principais: a) pelas variações cambiais dentro de um contexto de descasamento de moedas entre os passivos e ativos externos; b) grande parte desses estoques é denominada por preços de mercado (i.e., ações na Bolsa de Valores) e mudam de valor conforme suas cotações.

Nesse artigo partir-se-á da situação de que no âmbito mundial observou-se um fenômeno de crescente financeirização das transações externas com um expressivo aumento dos fluxos de capitais (Belluzzo, 2006; Chesnais, 2005; Camara \& Salama, 2005), enquanto o âmbito doméstico foi marcado por um processo de abertura da conta capital e financeira que inseriu diretamente o país ainda mais na liberalização financeira ocorrida no mundo (Belluzzo \& Almeida, 2002; Carneiro, 2002; Lopreato, 2006; Prates, 2006; Barbosa \& Souza, 2010).

Dessa forma, observou-se uma expressiva entrada de capitais de caráter mais especulativo e volátil na economia nacional, resultando num grande aumento do passivo externo líquido, sugerindo uma piora da vulnerabilidade externa da economia brasileira. Entretanto, o Governo Federal pode responder à crise global iniciada em 2008 adotando medidas monetárias e fiscais anticíclicas, possibilitando uma recuperação relativamente rápida da economia doméstica. Tal fato sugere o oposto, ou seja, uma melhora na situação da vulnerabilidade externa brasileira.

Essa contradição deve ser analisada pela ótica de uma importante transformação verificada nas contas externas nacionais, ou seja, ocorreu uma mudança significativa na composição da Posição Internacional de Investimentos (PII) brasileira, no sentido de que diminuiu a participação dos passivos externos denominados em moeda estrangeira, ficando menores do que as reservas internacionais, e aumentou a participação dos passivos externos denominados em moeda doméstica. Estes tendem a sofrer uma dupla desvalorização — câmbio e preço - em momentos de crise, portanto, a variação de preços dos estoques externos, nessa composição da PII, se mostra benéfica para o país nos momentos de maiores dificuldades, carac- 
terizando assim uma menor vulnerabilidade externa na esfera financeira, conforme se observou na crise global eclodida em 2008.

O objetivo desse artigo é analisar a vulnerabilidade externa decorrente da PII da economia brasileira na primeira década dos anos $2000^{2}$. Para tanto, além dessa seção introdutória, apresenta-se mais quatro seções. A próxima expõe a estruturação e os determinantes da evolução da PII. Na segunda seção é exibida a evolução da PII ao longo do período 2001-2010, enquanto na terceira faz-se uma análise dos fatores que levaram à evolução da PII ao longo desses anos. Por fim, na última seção são tecidas as considerações finais.

\section{POSIÇÃO INTERNACIONAL DE INVESTIMENTOS: ESTRUTURA E DETERMINANTES DE SUA EVOLUÇÃO}

Apresenta-se abaixo a Estrutura da Posição Internacional de Investimentos (PII). A PII é igual à diferença entre os ativos externos brutos de um país e seus passivos externos brutos. O cálculo e a apresentação da PII seguem a metodologia da quinta edição do Manual do Balanço de Pagamentos do Fundo Monetário Internacional (Simonsen \& Cysne, 2007). A categorização dos estoques de ativos e passivos na PII corresponde aos componentes da conta financeira do balanço de pagamentos $(\mathrm{BP})^{3}$ : investimento direto, investimento em portfólio, derivativos e outros investimentos. A Estrutura da PII apresentada abaixo faz uma segmentação da composição do passivo externo denominado em moeda estrangeira em relação à parte denominada em moeda doméstica.

$\mathrm{O}$ BP registra os fluxos entre o país e o exterior num determinado período contábil, ou seja, as transações efetivas entre residentes e não residentes da economia doméstica, geralmente em um ano. Já a PII complementa o BP, através do balanço de estoques. Seu objetivo é apresentar, a cada ponto no tempo, o total de ativos e passivos financeiros externos de uma economia (FMI, 1993).

Tradicionalmente não se utiliza o termo Posição Internacional de Investimentos nas discussões sobre os estoques externos, sendo primordialmente empregado o termo Passivo Externo Líquido (PEL). Existem duas maneiras diferentes de se calcular o PEL:

a) PEL1: O Passivo Externo Líquido 1 é calculado como igual ao déficit acumulado na conta-corrente do balanço de pagamentos; no caso brasileiro, tal valor é

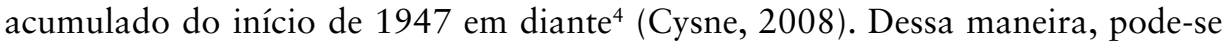

\footnotetext{
${ }^{2}$ Os motivos para essa delimitação são que os primeiros dados da PII brasileira são do ano de 2001, e 2010 representa o fim do governo Lula (2003-2010).

${ }^{3}$ Uma única diferença é a inclusão das reservas internacionais no item "Ativos de Reservas".

${ }^{4} \mathrm{O}$ motivo pelo qual se começa a contabilizar os déficits das transações correntes a partir do ano de 1947 reside no fato de que é a partir desse ano que o BC do país disponibiliza os dados do BP brasileiro.
} 
Quadro 1: Estrutura da Posição Internacional de Investimento (PII)

$\mathrm{PII}=$ Ativo Bruto (A) - Passivo Externo Bruto (B)

A) Ativo Externo Bruto (1+2)

1) Reservas Internacionais

2) Estoque de Investimento

2.1 Investimento direto no exterior

2.2 Investimento em carteira

2.3 Derivativos

2.4 Outros Investimentos
B) Passivo Externo Bruto $(3+4)$

3) Passivo em moeda estrangeira

3.1 Dívida Externa Bruta

3.2 Ações emitidas no exterior (Carteira)

3.3 Empréstimos intercompanhia (IDE)

4) Passivo em moeda doméstica

4.1 Títulos de renda fixa emitidos no país (Carteira)

4.2 Ações emitidas no país (Carteira)

4.3 Participação no capital (IDE)

Fonte: Banco Central; elaboração própria.

Notas: IDE: Investimento direto externo; Carteira: Investimentos em Carteira; Dívida Externa Bruta = Títulos

de renda fixa emitidos no exterior mais os Outros Investimentos.

considerar o PEL1 como uma aproximação dos reais valores do passivo externo líquido, porém, com a vantagem de facilitar os cálculos de sua elaboração.

b) PEL2: O Passivo Externo Líquido 2 é calculado como o estoque do passivo externo menos o estoque do ativo externo, ou seja, o simétrico, ou oposto, da Posição Internacional de Investimento, de forma que PII = -PEL2 (CYSNE, 2008).

Logo, utilizar-se-ão as seguintes identidades para explicar os conceitos de PEL1, PEL2 e PII:

$$
\begin{aligned}
& S T C_{t}=-S C F_{t}+\Delta \text { Res } \\
& \Delta P e l 1_{t}=-S T C_{t} \\
& -\sum_{i=1} S T C_{i}=P e l 1=D C C A \\
& P E L 2=P_{e x t}-A_{e x t} \\
& A_{e x t}-P_{e x t}=P I I=-P E L 2 \\
& P E L 2=P E L 1+V
\end{aligned}
$$

$\mathrm{X}_{\mathrm{t}}$ : Variável X no período $\mathrm{t}$

STC: saldo em transações correntes

SCF: saldo na conta capital e financeira

Res: reservas internacionais

$$
\begin{aligned}
& \text { PEL1: Passivo Externo Líquido1 } \\
& \text { PEL2: Passivo Externo Líquido2 }
\end{aligned}
$$

Além disso, é suposto, por simplificação, um passivo externo líquido igual a zero no final de 1946 (Simonsen \& Cysne, 2007). 
DCCA: déficit acumulado na conta-corrente do balanço de pagamentos

$\mathrm{A}_{\text {ext }}$ : Estoque de Ativos Externos

$\mathrm{P}_{\text {ext }}$ : Estoque de Passivos Externos

V: valorizações ou desvalorizações de ativos externos e passivos externos; monetizações ou desmonetizações de ouro; e alocações ou cancelamentos de DES

PII: Posição Internacional de Investimento

Dessa maneira, identifica-se por (1) que o saldo em transações correntes é igual ao oposto do saldo da conta financeira mais a variação das reservas internacionais, ou seja, um déficit em transações correntes no ano t, por exemplo, é financiado pela entrada de capitais estrangeiros no ano t e/ou pela queda das reservas internacionais, gerando, conforme se observa em (2), um aumento do passivo externo líquido 1 (PEL1) no ano $\mathrm{t}^{5}$.

Um aspecto fundamental dessa análise é que os fluxos financeiros por si sós não alteram o saldo da PII. Por (2) percebe-se que apenas o saldo das transações correntes afeta o saldo da PEL1. Isso ocorre porque, como se nota em (1), se o saldo das transações correntes for igual a zero, a variação das reservas internacionais vai ser igual ao saldo da conta financeira, ou seja, a magnitude da mudança no ativo externo vai ser igual à do passivo externo, não alterando o saldo da PII.

Já por (3), o PEL1 pode ser entendido como o déficit acumulado na conta corrente (DCCA) do BP, ou seja, pode-se perceber que o somatório (do oposto) dos saldos em conta-corrente gera o PEL1, retratando a parcela do estoque externo de uma economia que se explica unicamente em função do histórico de transações entre residentes e não residentes (Cysne, 2008).

Porém, conforme (6), o PEL1 e o PEL2 só serão iguais caso não ocorram as variações "V": valorizações ou desvalorizações de ativos e passivos; monetizações ou desmonetizações de ouro; e alocações ou cancelamentos de DES 6 .

Assim, deve-se lembrar que são as movimentações pelo lado financeiro do balanço de pagamentos que causam modificações nas posições patrimoniais, e representam transformações de estoque ou riqueza, afetando a contabilidade da PII; essas movimentações alteram o saldo do passivo externo líquido quando representam uma capacidade (superávit) ou necessidade (déficit) de financiamento decorrente das transações correntes. Todavia, como foi ressaltado, nem todas as mudanças patrimoniais decorrem de transações no BP, já que uma parte delas pode ser derivada das mencionadas variações ("V") de valor.

Nesse sentido, considerar-se-á o efeito GDN, caracterizado pelos ganhos com a detenção nominal de ativos financeiros e não financeiros decorrentes de variações

\footnotetext{
${ }^{5}$ Vale apontar que caso ocorra um superávit na conta financeira, no ano t, maior do que o déficit em transações correntes, no ano $t$, as reservas internacionais aumentam. Porém, mesmo nessa situação ocorre um aumento do passivo externo líquido 1, já que o passivo aumenta mais do que o ativo (no valor do déficit das transações correntes).
}

${ }^{6}$ DES: Direito Especial de Saque (FMI, 1993). 
nos preços (Araujo, 2008), dentre eles, a variação da taxa de câmbio. Assim, “[...] os GDN de ativos e passivos financeiros cujos valores são fixados em termos monetários são sempre nulos [...]" (Araujo, 2008, p. 271), como, por exemplo, as dívidas contraídas em dólar, já que essa é a moeda de referência na qual se calcula a PII brasileira. Um exemplo de GDN que não é nulo ocorre nos investimentos em Bolsas de Valores, já que os estoques sofrem variações de valor conforme as modificações das cotações das ações.

De acordo com Cysne, “[...] como se sabe da experiência internacional, passivos denominados em moeda doméstica são bem mais confortáveis em momentos de crises externas, tendo em vista que seu valor de mercado em moeda estrangeira costuma reduzir-se automaticamente em tais situações [...]" (Cysne, 2008, p. 4). A ideia implícita nesse raciocínio é que existe uma tendência de desvalorização cambial da moeda doméstica (brasileira) em momentos de crise, ou seja, pode-se supor que os passivos externos denominados em moeda estrangeira tornam-se mais onerosos nessas situações (de crise). Além disso, outra ideia implícita é de que os passivos externos denominados em moeda doméstica, num contexto de crise, diminuem de valor em termos da moeda estrangeira não só por conta da desvalorização cambial, mas também devido à queda de seus preços de mercado. Portanto, esses passivos externos brasileiros (denominados em moeda doméstica) tendem a sofrer um duplo efeito de desvalorização em momentos de conjuntura desfavoráveis.

\section{EVOLUÇÃO DA POSIÇÃO INTERNACIONAL DE INVESTIMENTOS BRASILEIRA NO PERÍODO 2001-2010}

Apresenta-se, na Tabela 1, a Posição Internacional de Investimentos (PII) da economia brasileira no período 2001-2010, sendo que os dados se referem ao dia 31 de dezembro de cada ano. A PII foi negativa durante todo o período, ou seja, o passivo externo bruto foi maior do que o ativo externo bruto nesses anos.

O fluxo de capitais no período refletiu-se na evolução da PII, seja pelo aumento do passivo externo bruto ou pela mudança de sua composição, expressa no aumento da participação do investimento direto e de portfólio, e pela diminuição da dívida externa. Pelo lado dos ativos, destaca-se o crescimento das reservas internacionais. Além disso, Bresser-Pereira (2012) aponta que esses fluxos de capitais tendem a desempenhar papel determinante na apreciação cambial brasileira, e que o desafio da política doméstica residiria na tentativa de evitar que tal situação comprometesse o desempenho comercial do país e que gerasse um processo de desindustrialização.

Já Biancarelli (2011) mostra que os investimentos em carteira representam a maior conta do passivo externo, o que significaria uma deterioração da situação patrimonial do país, já que considera esses investimentos mais voláteis e que podem sair do país com mais facilidade. Porém, o autor aponta que esse tipo de estoque externo tende a se desvalorizar duplamente em momentos de crise (efeito câmbio 
Tabela 1: Posição Internacional de Investimentos do Brasil, (US\$ bilhões), 2001-2010

\begin{tabular}{|c|c|c|c|c|c|c|c|c|c|c|}
\hline Discriminação & 2001 & 2002 & 2003 & 2004 & 2005 & 2006 & 2007 & 2008 & 2009 & 2010 \\
\hline PII (A-B) & $-265,0$ & $-230,5$ & $-272,5$ & $-297,6$ & $-316,6$ & $-368,9$ & $-540,5$ & $-283,4$ & $-600,8$ & $-677,4$ \\
\hline Ativo (A) & 107,1 & 112,9 & 134,2 & 148,5 & 168,2 & 238,9 & 379,8 & 408,2 & 479,1 & 616,3 \\
\hline $\begin{array}{l}\text { Investimento direto brasileiro no } \\
\text { exterior }\end{array}$ & 49,7 & 54,4 & 54,9 & 69,2 & 79,3 & 113,9 & 139,9 & 155,7 & 164,5 & 189,2 \\
\hline Investimentos em carteira & 6,4 & 5,8 & 7,0 & 9,4 & 10,8 & 14,4 & 19,5 & 14,9 & 16,5 & 37,6 \\
\hline Derivativos & 0,0 & 0,1 & 0,1 & 0,1 & 0,1 & 0,1 & 0,1 & 0,6 & 0,4 & 0,8 \\
\hline Outros investimentos & 15,1 & 14,7 & 23,0 & 16,9 & 24,2 & 24,6 & 39,9 & 43,2 & 59,1 & 100,0 \\
\hline Ativos de reservas & 35,9 & 37,8 & 49,3 & 52,9 & 53,8 & 85,8 & 180,3 & 193,8 & 238,5 & 288,6 \\
\hline Passivo (B) & 372,1 & 343,4 & 406,7 & 446,1 & 484,8 & 607,7 & 920,3 & 691,6 & 1079,9 & 91293,6 \\
\hline Investimento estrangeiro direto & 121,9 & 100,9 & 132,8 & 161,3 & 181,3 & 220,6 & 309,7 & 287,7 & 400,8 & 472,6 \\
\hline Investimentos em carteira & 151,7 & 137,4 & 166,1 & 184,8 & 232,4 & 303,6 & 509,6 & 287,5 & 561,8 & 656,3 \\
\hline Derivativos & 0,0 & 0,2 & 0,1 & 0,3 & 0,2 & 0,4 & 1,8 & 2,5 & 3,4 & 3,8 \\
\hline Outros investimentos & 98,3 & 105,0 & 107,7 & 99,8 & 70,9 & 83,1 & 99,2 & 113,9 & 113,8 & 161,0 \\
\hline
\end{tabular}

Fonte: Banco Central.

Nota: Os dados se referem ao dia 31 de dezembro de cada ano.

e queda de preços), diminuindo os eventuais problemas que possam causar nesses momentos de dificuldade.

Além disso, nota-se, pela Tabela 1, que o Brasil tem sido um importante receptor de investimentos diretos estrangeiros, porém, recentemente, as corporações brasileiras têm aumentado os investimentos no exterior, configurando um novo padrão de inserção no sistema produtivo e comercial mundial, com expressivo crescimento desse tipo de ativo externo.

Gráfico 1: Composição do Passivo Externo brasileiro, (\%), 2001-2010.

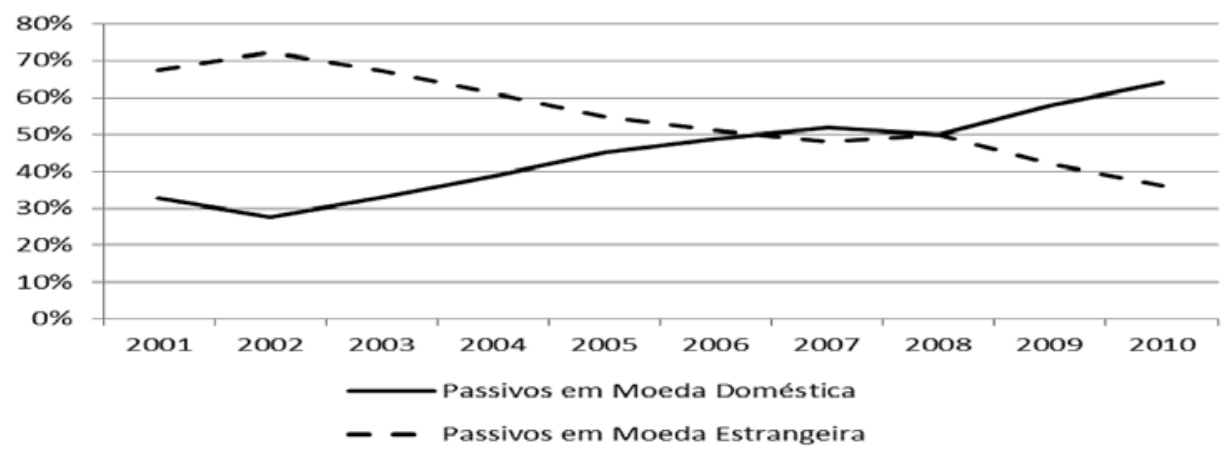

Fonte: Banco Central; elaboração própria.

Nota: Passivos em Moeda Doméstica foi considerado como a soma entre os títulos de renda fixa emitidos no país, as ações emitidas no país e o investimento direto estrangeiro relativo a "participação no capital".

Um fator fundamental a apresentar, conforme se nota no Gráfico 1, é a mudan- 
ça na composição do passivo externo brasileiro, sendo que a parcela denominada em moeda estrangeira diminuiu sua participação de aproximadamente $67 \%$ para $36 \%$ no total do mesmo ao longo do período 2001-2010. Em contrapartida, o passivo externo denominado em moeda doméstica apresenta um grande aumento de participação. Dessa forma, conforme apresentado em seção anterior, considerar-se-á que a economia brasileira reduziu sua vulnerabilidade externa decorrente da Posição Internacional de Investimentos, afinal, esta mudança na composição do passivo externo representa menores problemas em momentos de crise $^{7}$.

Gráfico 2: Dívida Externa e Reservas Brasileiras (US\$ bilhões), 2001-2010

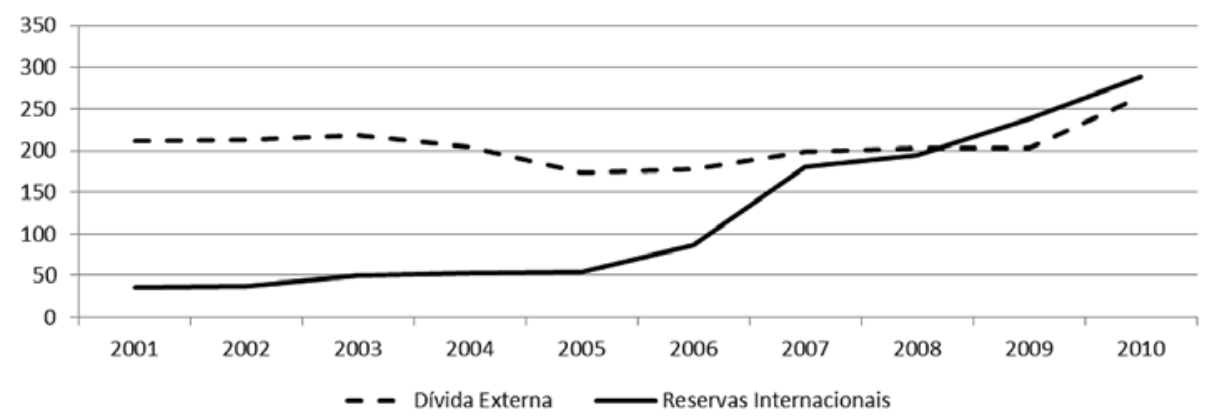

Fonte: Banco Central.

Nota: A Dívida Externa foi considerada como a soma entre os títulos de renda fixa emitidos no exterior mais os outros investimentos.

Entretanto, deve-se fazer uma ressalva ao raciocínio anterior. Não obstante os efeitos benignos desse tipo de composição do passivo externo sobre a vulnerabilidade externa, ou seja, decorrentes da preponderância da parte denominada em moeda doméstica vis-à-vis a denominada em moeda estrangeira, é fundamental confrontar esses dados com a dívida externa líquida $(\mathrm{DEL})^{8}$.

Nesse sentido, vide o Gráfico 2, observa-se mais uma mudança positiva para a vulnerabilidade externa da economia brasileira, afinal, as reservas internacionais se tornam maiores do que a dívida externa, fazendo com que a dívida externa líquida se torne negativa, significando menores dificuldades em momentos de crise.

Em suma, pode-se considerar que a vulnerabilidade externa da economia brasileira, sob a ótica do presente estudo, diminuiu, afinal, o país conta com a segurança, nos momentos de crise, de que suas reservas internacionais cubram a dívida externa. Completando o raciocínio, o passivo externo denominado em moeda doméstica tende a sofrer um duplo efeito de desvalorização nos momentos de crise e

\footnotetext{
${ }^{7}$ Adiante veremos como evoluiu a PII durante a crise iniciada em 2008.

${ }^{8}$ A Dívida Externa Líquida (DEL) é obtida pela Dívida Externa bruta subtraída das Reservas Internacionais, ou seja, por um passivo externo que é denominado em moeda estrangeira e causa dificuldades em momentos de crise externa, e pela parte do ativo externo que num momento de tensão e dificuldades cambiais pode ser imediatamente utilizado para amenizar o problema.
} 
este se tornou majoritário na composição da PII. Logo, diminui o ímpeto de saída de divisas justamente nas situações de maiores dificuldades, já que a "porta de saída" é estreita e implica grandes perdas para os investidores que quiserem retirar seu capital do país nesse momento. Para verificar tal hipótese, pode-se analisar o ano de 2008, quando eclode a grande crise financeira mundial. Observa-se, pela Tabela 1, que o passivo externo sofre uma grande perda de valor justamente no ano da crise ${ }^{9}$. Dessa forma, considerar-se-á que o Brasil não foi tão afetado pela crise justamente por conta dessa diminuição da vulnerabilidade externa decorrente da composição da PII.

\section{DETERMINANTES DA EVOLUÇÃO DA POSIÇÃO INTERNACIONAL DE INVESTIMENTOS BRASILEIRA: ANÁLISE DO PERÍODO 2001-2010}

$\mathrm{Na}$ Tabela 2 é feita uma estimativa dos fatores que levaram à variação anual do saldo da PII, comparando essa variação com o saldo das transações correntes lembrando que os fluxos financeiros por si sós não alteram o saldo da PII. A diferença de valor entre essas duas variáveis (variação anual do saldo da PII e do saldo anual das transações correntes) foi atribuída ao fator GDN — decorrente das variações de valor dos estoques. Portanto, pela metodologia adotada, a variação anual do saldo da PII pode ser causada por dois fatores: a) pelo saldo das transações correntes; b) pelo efeito GDN.

Tabela 2: Evolução da PII e das Transações Correntes (US\$ bilhões).

Determinantes das variações do saldo da PII, (\%), (2001-2010)

\begin{tabular}{lccccccccccc}
\hline Discriminação & 2001 & 2002 & 2003 & 2004 & 2005 & 2006 & 2007 & 2008 & 2009 & 2010 & Total \\
\hline TC & $-23,2$ & $-7,6$ & 4,2 & 11,7 & 14,0 & 13,6 & 1,6 & $-28,2$ & $-24,3$ & $-47,4$ & $-85,7$ \\
\hline & & & & & & & & & & \\
\hline PII & $-265,0$ & $-230,5$ & $-272,5$ & $-297,6$ & $-316,6$ & $-368,9$ & $-540,5$ & $-283,4$ & $-600,8$ & $-677,4$ & s.v. \\
Variação anual PII & S.v. & 34,4 & $-42,0$ & $-25,1$ & $-19,0$ & $-52,3$ & $-171,6$ & 257,1 & $-317,4$ & $-76,6$ & $-412,4$ \\
\hline & & & & & & & & & & & \\
\hline TCNariação anual PII & s.v. & $-22 \%$ & $-10 \%$ & $-47 \%$ & $-74 \%$ & $-26 \%$ & $-1 \%$ & $-11 \%$ & $8 \%$ & $62 \%$ & $21 \%$ \\
GDNNariação anual PII & s.v. & $122 \%$ & $110 \%$ & $147 \%$ & $174 \%$ & $126 \%$ & $101 \%$ & $111 \%$ & $92 \%$ & $38 \%$ & $79 \%$ \\
\hline
\end{tabular}

Fonte: Banco Central; elaboração Própria.

Notas: (1) TC = Transações Correntes; PII = Posição Internacional de Investimentos; GDN = ganho de detenção nominal; s.v. = sem valor; (2) Os dados da Posição Internacional de Investimentos se referem ao dia 31 de dezembro de cada ano; (3) Os dados das Transações Correntes se referem ao valor ao longo do ano.

\footnotetext{
${ }^{9}$ Passando de US\$ 920 bilhões em 2007 para US\$ 692 bilhões em 2008, especialmente pela expressiva queda do estoque dos investimentos em carteira (que diminuem em mais de US\$ 200 bilhões no ano de 2008). Enquanto isso, o ativo externo brasileiro até aumenta durante esse ano.
} 
Assim, por exemplo, em 2004 o saldo das transações correntes foi positivo em US\$ 11 bilhões (Tabela 2) e a variação do saldo da PII no mesmo ano foi de US\$ -25 bilhões (Tabela 2), ou seja, pela metodologia adotada concluímos que $-47 \%$ da variação da PII para esse ano foi causada pelo déficit das transações correntes e em $147 \%$ ocasionada pelo efeito GDN (Tabela 2). Isso implica que, apesar do saldo positivo em transações correntes, o passivo externo líquido aumentou no ano de 2004. Esse resultado, não trivial, demarca uma nova configuração da evolução dos estoques externos, pois o "endividamento" líquido de um país pode aumentar mesmo quando ele apresentar uma capacidade de financiamento decorrente de saldos positivos nas transações correntes. Esse fato, aparentemente contraditório, é explicado pelas variações de preços dos estoques externos.

Analisando-se a evolução do saldo da PII anual observa-se como a identidade $(2)^{10}$ apresentada neste trabalho é insuficiente para explicar as mudanças ocorridas no saldo do passivo externo líquido, fazendo com que as variações " $V$ ”, representadas pelo efeito GDN, passem a ser a variável mais importante na explicação dos resultados. Outra evidência apontada nesse sentido é que o déficit acumulado em transações correntes no período 2001-2010 foi de US\$ 85 bilhões, enquanto a variação da PII foi de US\$ -412 bilhões. Pela Tabela 2, o efeito GDN explicou 79\% da variação da PII durante o período 2001-2010. Além disso, na análise anual, o efeito GDN explica na maioria das vezes mais de $100 \%$ da evolução da PII, enquanto os saldos em transações correntes geralmente não explicam nem o sinal da variação.

Portanto, se deduz que a dinâmica de evolução dos estoques externos adquire certa autonomia em relação aos saldos das transações correntes, já que o efeito GDN passa a ser o principal determinante dessa evolução. Tal processo é gerado por dois fatores principais: a) pelas variações cambiais dentro de um contexto de descasamento de moedas entre os passivos e ativos externos; b) grande parte desses estoques representa a criação de capital fictício ${ }^{11}$ descrita por Marx, no sentido de que a valorização do capital fica crescentemente relacionada com a variação de preço dos ativos, ou seja, no esquema D-D' preconizado pelo autor.

Essa criação de capital fictício e a possibilidade de aumentar o passivo externo líquido mesmo com um equilíbrio em transações correntes, decorrente de variações de preços dos estoques, enseja a hipótese de que a vulnerabilidade externa brasileira aumentou desmesuradamente. Nesse sentido, muitos economistas, dentre eles Gonçalves (2009) e Sampaio Jr. (2010), enfatizam o grande crescimento do passivo externo líquido como um efeito negativo sobre as contas externas brasileiras. Con-

\footnotetext{
${ }^{10}$ A identidade (2) mostrou que: $\triangle P E L_{1}=-S T C_{t}$.

11 "E deve entender-se por acumulação do capital-dinheiro notadamente a acumulação desses direitos sobre a produção, acumulação segundo o preço de mercado, o valor-capital ilusório deles” (Marx, 1867, p. 621; grifo nosso).
} 
tudo, o caráter fictício desses estoques se manifesta nas crises, portanto, justamente no momento em que a vulnerabilidade externa irá se manifestar os estoques externos podem diminuir de valor consideravelmente.

Assim, vale destacar a forma como o Governo Federal respondeu à crise internacional iniciada em 2008, com uma postura muito diferente das crises internacionais anteriores, já que as autoridades brasileiras adotaram medidas monetárias e fiscais anticíclicas. O principal objetivo era recuperar o nível de atividade econômica o mais rápido possível, tentando manter certo nível de demanda efetiva e evitando que a crise internacional contaminasse o sistema financeiro brasileiro. $\mathrm{O}$ Brasil se recuperou, relativamente, bastante rápido, e a capacidade demonstrada pelo país em absorver os impactos da crise internacional melhorou a percepção dos mercados em relação ao país (Barbosa \& Souza, 2010).

Nossa hipótese é de que o governo brasileiro pôde atuar dessa forma preponderantemente por conta da diminuição da vulnerabilidade externa decorrente da PII de sua economia. Isso fica evidente, de acordo com a Tabela 2, pela expressiva melhora da PII brasileira de 2007 para 2008, passando de aproximadamente US\$ -540 bilhões para US\$ -283 bilhões. Tal efeito, de acordo com nossa metodologia, foi em $111 \%$ decorrente do efeito GDN, ou seja, durante a crise a variação de preços dos estoques externos se mostrou benéfica para o país - vale registrar, para os que acreditam que essa queda de valor da PII possa ser decorrente da saída de capitais do país, que os dados do Banco Central brasileiro apontam que em 2008 ocorreu um superávit da conta capital e financeira de US\$ 29 bilhões ${ }^{12}$. Portanto, a pressão por geração de divisas decorrente da saída de passivos externos foi amenizada durante a crise, permitindo um maior grau de autonomia da política doméstica e evitando que os credores externos ditassem os rumos econômicos do país.

\section{CONSIDERAÇÕES FINAIS}

Este artigo teve como objetivo investigar a evolução da vulnerabilidade externa da economia brasileira na primeira década dos anos 2000. As análises sobre o tema, geralmente, são focadas na questão do comércio exterior. Partindo da análise da esfera financeira, pretendeu-se inferir de que forma a vulnerabilidade externa é influenciada pela magnitude e composição da Posição Internacional de Investimentos (PII).

Considerou-se que no âmbito mundial ocorreu um fenômeno de crescente financeirização das transações externas com um expressivo aumento dos fluxos de capitais, enquanto o âmbito doméstico foi marcado por um processo de abertura

\footnotetext{
${ }^{12}$ A crise eclodiu em setembro de 2008, com a quebra do Lehman Brothers. Os dados mensais brasileiros da conta capital e financeira indicam, em milhões de dólares, os seguintes valores: set/2008: 5.274; out/2008: -9.066; nov/2008: -8.980; dez/2008: -6.701; jan/2009: 273 (Banco Central).
} 
da conta capital e financeira que inseriu diretamente o país ainda mais na liberalização financeira ocorrida no mundo.

Uma das principais consequências desse processo foi o aumento da participação dos investimentos estrangeiros em carteira e de investimentos diretos na economia brasileira, representado um efeito contraditório sobre a vulnerabilidade externa do país. Por um lado, a evolução da PII ficou cada vez mais independente dos saldos em transações correntes; isso porque o efeito GDN (ganhos de detenção nominal), marcado pelas variações de preços dos estoques externos, passa a ser a variável determinante da evolução do saldo da PII. Assim, observou-se um grande aumento do passivo externo líquido no valor de US\$ 412 bilhões. Enquanto isso, o déficit acumulado em transações correntes no período analisado foi de US\$ 85 bilhões.

Por outro lado, aponta-se que essas variações de valor dos estoques externos estão relacionadas com a mudança na composição da PII brasileira, que diminuiu a participação dos passivos externos denominado em moeda estrangeira e aumentou a dos denominados em moeda doméstica. Além disso, ocorreu grande aumento das reservas internacionais, permitindo ao país obter uma dívida externa líquida negativa. Logo, e levando-se em conta que esses passivos externos denominados em moeda doméstica sofrem de uma dupla desvalorização - efeito câmbio e preço - em momentos de crise, concluiu-se, pela ótica do presente estudo, pela diminuição da vulnerabilidade externa da economia brasileira.

Tal fato foi comprovado pela grande crise originada em 2008, quando o Governo Federal pôde responder à mesma adotando medidas monetárias e fiscais anticíclicas (postura muito diferente das crises internacionais anteriores), possibilitando uma recuperação relativamente bastante rápida da economia. Um dos fatores que permitiu essa política foi a expressiva melhora da PII brasileira de 2007 para 2008, passando de aproximadamente US $\$-540$ bilhões para US\$ -283 bilhões. Tal efeito, de acordo com nossa metodologia, foi em $111 \%$ decorrente do efeito GDN, ou seja, durante a crise a variação de preços dos estoques externos se mostrou benéfica para o país, fazendo com que a pressão por geração de divisas decorrente da saída de passivos externos fosse amenizada, permitindo um maior grau de autonomia da política doméstica e evitando que os credores externos ditassem os rumos econômicos do país.

Assim, a inserção externa realizada pela economia brasileira, pelo lado financeiro, através da abertura da conta capital e financeira, parece levar a uma situação de excesso de entrada de capitais estrangeiros (em relação às necessidades das transações correntes), permitindo ao mesmo tempo a formação de reservas internacionais — que tendem a melhor a solvência externa — com a apreciação cambial - que tende a piorar os déficits das transações correntes. Tal efeito contraditório sobre as contas externas parece ter levado a uma composição da PII que diminuiu a vulnerabilidade externa da economia brasileira, ao menos no curto prazo. 
Entretanto, não se discutiram três questões importantes, mas que fogem ao escopo do artigo: a) qual o custo para o país de manter esse tipo de composição da PII (dado pelo diferencial de rentabilidade entre os ativos e passivos externos)? b) essa composição da PII é sustentável no longo prazo? c) dado que na crise o Brasil teve um efeito benéfico pela diminuição de valor do seu passivo externo, isso implica, necessariamente, que outros países tiveram uma queda de seu ativo externo nesse período; quais foram esses países e qual a consequência para os mesmos?

Em suma, diante desse quadro de diminuição da vulnerabilidade externa decorrente da PII, enseja-se, quando comparado com a recente história econômica brasileira, a possibilidade da adoção de políticas de desenvolvimento, sem causar temores tão agudos de manifestação da restrição externa caso ocorra uma crise internacional. Dito de outra maneira, a nova composição da PII brasileira permite um maior raio de manobra para a política econômica doméstica.

\section{REFERÊNCIAS BIBLIOGRÁFICAS}

ARAUJO, M. S (2008) “Estatísticas do Setor Externo”. In: FEIJÓ, C.A. (et al.), Para Entender a Conjuntura Econômica, Barueri, Ed. Manoele.

BARBOSA \& SOUZA (2010) “A inflexão do governo Lula”. In: SADER, E. e GARCIA, M. A. Brasil, Entre o Passado e o Futuro. São Paulo, Ed. Fundação Perseu Abramo, Boitempo.

BELLUZZO, L.G.M. (2006) "As transformações da economia capitalista no pós-guerra e a origem dos desequilíbrios globais”. In: CARNEIRO, R. (Org.), A Supremacia dos Mercados e a Política Econômica do Governo Lula. São Paulo: Editora UNESP.

BELLUZZO, L.G.M; ALMEIDA, J. G. (2002) Depois da Queda. Rio de Janeiro: Civilização Brasileira. BIANCARELLI, A. (2011) "Riscos na travessia? O financiamento externo e os desafios futuros da economia brasileira”. In: CARNEIRO, R. e MATISJACIC, M. Desafios do Desenvolvimento Brasileiro. Brasília.

BRESSER-PEREIRA, L. C. (2012) "Structuralist macroeconomics and the new developmentalism". Revista de Economia Política, 32 (3): 347-366.

CAMARA, M. \& SALAMA, P. (2005) "A inserção diferenciada dos países em desenvolvimento na mundialização financeira”. In: CHESNAIS, F. A Finança Mundializada, São Paulo: Boitempo Editorial.

CARNEIRO, R. (2002) Desenvolvimento em Crise. São Paulo: Editora Unesp, IE-UNICAMP.

CHESNAIS, F. (2005) “O capital portador de juros”. In: CHESNAIS, F. (Org.). A Finança Mundializada, São Paulo: Boitempo Editorial.

CYSNE, R. P. (2008) Passivo Externo Líquido Versus Dívida Externa Líquida, 2008. Disponível em:<www.fgv.br/professor/rubens/HOMEPAGE/ARTIGOS_E_REPORTAGENS_DE_POL_ ECON/Artigos_Publicados/2008/Passivo\%20Externo.pdf>. Acesso em 16 de nov 2011.

FMI (1993) Quinta edição do Manual do Balanço de Pagamentos do Fundo Monetário Internacional. GONÇALVES, R. (1999) “Maxidesvalorização, vulnerabilidade externa e a crise brasileira”. Revista Ensaios FEE, Vol. 27, núm 1, pág 50-69, Porto Alegre (RS). (2005) Economia Política Internacional. Rio de Janeiro: Elsevier.

(2009) Vulnerabilidade Externa e Crise Econômica no Brasil. Disponível em: http://www.ie.ufrj. br/hpp/intranet/pdfs/vulnerabilidade_externa_e_crise_economica_no_brasil_marco_2009.pdf. Acesso em: 23 out 2012. 
LOPREATO, F. L. (2006) “A política fiscal brasileira. In: CARNEIRO, R. A Supremacia dos Mercados e a Política Econômica do Governo Lula. São Paulo: Ed. UNESP.

MARX, K. ([1867] 2008). O Capital- Livro III. Rio de Janeiro: Civilização Brasileira.

PRATES, D. M. (2006) “A inserção externa da economia brasileira no governo Lula. In: CARNEIRO, R. A Supremacia dos Mercados e a Política Econômica do Governo Lula. São Paulo: Ed. Unesp.

SAMPAIO Jr, P. A. (2010). “O Brasil não é maior do que a crise. Jornal dos Economistas, $\mathrm{N}^{\circ} 255$, outubro de 2010, pág. 5-6.

SIMONSEN, M. H. \& CYSNE, R. P. (2007) Macroeconomia. $3^{\text {a }}$ edição. Rio de Janeiro: Editora Atlas. 